\title{
A MODEL FOR DETERMINING THE SAFETY LEVEL OF OCCUPATIONAL WORK USING ACCIDENTS AND INJURIES MEASUREMENT PARAMETERS: A REVIEW
}

\author{
T.A. YUSUF ${ }^{1 *}$, O.M. SANUSI ${ }^{2}$, H.O. ADEYEMI ${ }^{3}$ \\ ${ }^{1}$ Mechanical Engineering Department, University of Agriculture P.M.B 2373 Makurdi \\ Nigeria \\ ${ }^{2}$ Mechanical Engineering Department, Federal University, P.M.B 373 Oye Ekiti Nigeria \\ ${ }^{3}$ Agricultural and Mechanical Engineering Department, Olabisi Onabanjo University, Ago- \\ Iwoye Nigeria
}

\begin{abstract}
Frequency Rate (FRR), Fatality Rate (FAR) and Severity Rate (SR) are common parameters used in communicating the research output of occupational accidental injuries. These parameters have been used to provide a model for classifying an occupational work activity into five level/degrees of safety ranging between Very Safe and Highly Unsafe. With a work activity defined as $\mathrm{x}: \mathrm{x} \leq 0.01, \mathrm{x} \leq 0.003$ or $\mathrm{x} \leq 0.03$ indicates Very Safe Level while $\mathrm{x}>0.04, \mathrm{x}>0.015$ or $\mathrm{x}>0.11$ indicates Highly Unsafe Level according to FRR, SR and FAR respectively. A case study is provided from an existing work to experiment the application of the model.
\end{abstract}

Keywords: occupational injuries, industrial accident, fatality rate, severity rate, fatality rate, safety model

\section{INTRODUCTION}

By the estimation of [1], 2.3 million deaths occurred annually across the countries for reasons attributed to work. In a span of just four years in a manufacturing industry, about one hundred and twenty-five thousand naira (N125, 000.00 ) is being expended on the treatment of injured employees while 1,245 man-hours of production are being lost [2].

Increasing daily demands for raw materials and finished products has stepped up the competition and network in production activities. With the attendant sophistications in technology and expansion of workforce, the need for a safety and minimization of occupational accidents has become a matter of a serious concern to industrial managers, government, safety professionals and researchers. Azadeh-Fard et al. [3] have lamented this with their remark that recent efforts to improve occupational health and safety is yet to satisfactorily stem occupational accidents resulting in serious injury and death yearly. They also viewed data about the leading causes of incidents or risk factors as an essential requirement in the Prevention and control of occupational injuries.

Manufacturing industries engage the services of personnel at various stages or lines of production activities. Literature reviews have indicated the strong influence of work environment and condition on the occurrence of occupational accidents. The essence of undertaking researches in those environments is to determine the level of risks or safety to which the personnel are susceptible. Determining the level of safety is vital to government and

\footnotetext{
* Corresponding Author: email: yusuf.taofeek@uam.edu.ng

(c) 2016 Alma Mater Publishing House
} 
regulatory bodies to ascertain the level of indifference to the safety standards and/or negligence of the welfare of the workforce existing in work places. It may also be a factor for issuing warrant of immediate closure of highly unsafe work environment. It generally enhances policies for the management and regulation of industrial activities. Level of Safety can also be used in the rating or ranking of the industries to engender competitions for improved safety standards.

Tools of risk assessment analysis exist but are less related to records of accidents and injuries in the workplaces. Dumrak et al. [4] in his study on accident severity categorized occupational injuries as Minor-Incidents (if accompanied with no lost days or hospitalization); moderate-accidents (if accompanied with no lost days but hospitalization); Serious - Incidents (with 1-3 lost days); Severe - Incidents (with 4-10 lost days); Critical Incidents (with more than 10 lost days) and Fatal - Incidents (with un-survivable conditions). However, a model which relates the number of hours/days lost with the man-hour worked or employee hours of exposure may be essential. Therefore, there is need for a new approach where the level of safety may be accessed based on accident/injuries data.

Data on accident or injuries related matters when investigated have usually been quantified using Frequency Rate (FRR), Fatality Rate (FAR) and Severity Rate (SR) among other similar conventional terminologies. These parameters are estimated based on the recorded number of injuries or death cases, days lost and man-hours worked. Man-hours worked or employee hours of exposures in these parameters' estimation varies in the literatures as 1000000 [2], 200000 [5] or $100000[1,3]$.

However, rather than using these parameters to predict, or determine the level of safety of concerned work activities, the available data are merely stated and left as numerical values in various research communications. Meanwhile, the ability of interested audience to derive such judgement or inference from these parameters is the major goal of an evaluation work on any accident/injury related occupational activities. Existence of such prediction model facilitates the decision making on a particular job activities or level of safety management practice existing in an industry. It enhances regulation and quality control by the government, safety management professionals or accident monitoring authorities. It has been thoughtfully remarked by [6] that risk assessment tools are quite important for safety practitioners.

Nonetheless, despite the increasing research focus on accident and injuries matters, predictive model based on FRR, FAR and SR are rare if ever existing. Literature survey revealed that predictive models for determining when and where accidents would occur during occupational activities have been advanced [7]. According to the same author, the existence of varieties of such tools is abound in practice. However, the focus of this review study is a model to predict or determine the degree or level of safety of a particular work activity. This shall be accomplished with an illustration of its application using a case study of an existing research from the literatures.

\section{METHODOLOGY}

\subsection{Injuries/Accident Frequency Rate}

Yusuf et al [2] defined Accident Frequency rate as total number of accidents per million (1000000) Man-Hours Worked while [5] defined Injuries Frequency Rate as the number of compensable injuries per 200000 employeehours of exposure. Compensable injuries or accidents are work-related injuries or accidents that require compensation from employers or workplace compensation board because they arose during the course (or as a result) of work.

\subsubsection{Assumption and Calculation}

- Leaving out the difference in the basic factor of per 1 or 0.2 million man-hours worked appearing in both definitions, a common expression for Frequency Rate for accidents or injuries can be presented as:

$$
\text { Frequency Rate }=\frac{\text { Total Number of Accidents } / \text { Injuries }}{\text { Total Hours Worked }(\text { THW })}
$$

- If a man-hour works (MHW) per day $=8$ hours (8am-4:00pm assumed). In three working days, total Hours worked $($ THW) $=8 \times 3=24$ hours; 
- In three days, a man is not expected to have an accident/injury more than once under a normal working environment and condition. Thus, the maximum number of expected accident/injuries during these periods is 1 which may vary within range $0-1$ at a reduction level of 0.25 i.e $0,0.25,0.5,0.75$ and 1 ;

- Each of these values are made in succession as numerators of equation (1) with THW=24hours as denominator. Thus, Frequency Rates are respectively obtained as 0, 0.01, 0.02, 0.03 and 0.04 .

\subsubsection{Frequency Rate Based Model}

The level of safety of any work activities, once the value of frequency Rate is determined can be classified and determined using this model shown in Table 1.

Table 1. Prediction Model for Work activities based on Frequency rate.

\begin{tabular}{|l|c|c|}
\hline S/N & Frequency Rate* & Safety Level of Work Activities (x) \\
\hline 1 & $\mathrm{x} \leq 0.01$ & Very Safe \\
\hline 2 & $0.01<\mathrm{x} \leq 0.02$ & Moderately Safe \\
\hline 3 & $0.02<\mathrm{x} \leq 0.03$ & Less Safe (critical) \\
\hline 4 & $0.03<\mathrm{x} \leq 0.04$ & Unsafe (Highly Critical) \\
\hline 5 & $\mathrm{x}>0.04$ & Highly Unsafe \\
\hline
\end{tabular}

*The values provided are yet to be multiplied by any of the conventional factors of 1000000, 200000 or 100000 man-hours (whichever applicable). If the FRR available in the case study is already multiplied by the chosen factor, a division would be carried out to determine the safety level provided in this model.

\subsection{Injuries/Accident Severity Rate}

Yusuf et al. [2] determined Accident Severity Rate by total Man-Hours Lost per million Man-Hours Worked while [5] defined Injury Severity Rate as a number that relates total days lost due to compensable injuries to the total hours worked during a specific period. The former used per million man-hours in their calculation while the latter expressed the formula per 200000 man-hours of exposures. There is also another variation of whether the numerator in this expression is hours or days lost. Yusuf et al. [2] used it in hours while [5] expressed it in days and it appears that more literatures favored the latter.

\subsubsection{Assumption and Calculation}

- Leaving out the difference in the basic factor of per 1 or 0.2 million man-hours worked appearing in both definitions and expressing the numerator as days lost as presented by [5], common expression for Severity Rate for accidents or injuries can be presented as:

$$
\text { Severity Rate }=\frac{\text { Number of Days Lost }}{\text { Total Hours Worked }(\text { THW })}
$$

- It is assumed that a man hour loss of more than three hours is not expected within a man-hour works $(\mathrm{MHW})$ per day $=8$ hours $(8 \mathrm{am}-4: 00 \mathrm{pm}$ assumed). If three working days, total Hours worked $(\mathrm{THW})=$ $8 \times 3=24$ hours is assumed, a man-hour loss of 9 hours at maximum can be estimated. This assumption is far at variance with that of [4] who categorized an accident with 1-3 days lost as serious incident without reference to THW;

- If this 9 hours lost maximum is varied at reduction level of 9, 6, 3, 1.5, and 0 hours within this 24 hours (3days) of total hours worked, their conversion in days would give $0.375,0.25,0.125,0.063$ and 0 days;

- $\quad$ Each of these values is made in succession as numerators of equation (2) with THW $=24$ Hour as denominator. Thus, Severity Rates are respectively obtained as 0.015, 0.010, 0.005, 0.003 and 0.000.

\subsubsection{Severity Rate Based Model}

The level of safety of any work activities, once the value of Severity Rate is determined can be classified and determined using this model shown in Table 2.

\subsection{Injuries/Accident Fatality Rate}

IAPA [5] defined Fatality as death resulting from an accident. According to Yusuf et al. [2], Case Fatality Rate is determined by the number of death cases per hundred injuries cases. They expressed it as: 


$$
\text { Fatality Rate }=\frac{\text { Death Cases }}{\text { Injuries Cases }} \cdot 100
$$

Table 2. Prediction Model for Work activities based on Severity rate.

\begin{tabular}{|c|c|c|}
\hline S/N & Severity Rate* & Safety Level of Work Activities (x) \\
\hline 1 & $\mathrm{x} \leq 0.003$ & Very Safe \\
\hline 2 & $0.003<\mathrm{x} \leq 0.005$ & Moderately Safe \\
\hline 3 & $0.005<\mathrm{x} \leq 0.01$ & Less Safe (critical) \\
\hline 4 & $0.01<\mathrm{x} \leq 0.015$ & Unsafe (Highly Critical) \\
\hline 5 & $\mathrm{x}>0.015$ & Highly Unsafe \\
\hline
\end{tabular}

*The values provided are yet to be multiplied by any of the conventional factors of 1000000 or 200000 or 100000 man-hours (whichever applicable). If the SR available in the case study is already multiplied by the chosen factor, a division would be carried out to determine the safety level provided in this model.

\subsubsection{Assumption and Calculation}

- It is assumed that 2 or more than cases of death is abnormal in every 20 cases of accident/injuries under normal standard working condition and environment.

- If these assumed cases of death have a degree between 0-2 at reduction level of 2,1.5, 1 and 0.5 , then the ratio of death to injuries in every 20 cases will respectively be $2: 18,1.5: 18.5,1: 19$ and $0.5: 19.5$

- $\quad$ Each of these ratios respectively gives $0.11,0.08,0.05$ and 0.03 .

\subsubsection{Fatality Rate Based Model}

The level of safety of any work activities, once the value of Fatality Rate is determined can be classified and determined using this model shown in Table 3.

Table 3. Prediction Model for Work activities based on Fatality rate.

\begin{tabular}{|l|c|c|}
\hline S/N & Fatality Rate* & Safety Level of Work Activities (x) \\
\hline 1 & $\mathrm{x} \leq 0.03$ & Very Safe \\
\hline 2 & $0.03<\mathrm{x} \leq 0.05$ & Moderately Safe \\
\hline 3 & $0.05<\mathrm{x} \leq 0.08$ & Less Safe (critical) \\
\hline 4 & $0.08<\mathrm{x} \leq 0.11$ & Unsafe (Highly Critical) \\
\hline 5 & $\mathrm{x}>0.11$ & Highly Unsafe \\
\hline
\end{tabular}

*The values provided are yet to be expressed in percentage or multiplied by 100. If the FAR available in the case study is already in percentage, a division would be carried out to determine the safety level provided in this model.

\section{GENERALIZED MODEL AND SAMPLE APPLICATIONS}

The generalized model for determining the safety level of a work activity using the three parameters in presented in Table 4.

Table 4. Generalized Model for Determining Level of Safety of Work activities.

\begin{tabular}{|l|l|c|c|c|}
\hline \multirow{2}{*}{ S/N } & \multirow{2}{*}{$\begin{array}{c}\text { Work Safety Level } \\
(\mathbf{x})\end{array}$} & \multicolumn{3}{|c|}{ Predictive Model* $^{*}$} \\
\cline { 3 - 5 } & & Frequency Rate** & Severity Rate $^{* *}$ & ${\text { Fatality } \text { Rate }^{+}}^{*}$ \\
\hline 1 & Very Safe & $\mathrm{x} \leq 0.01$ & $\mathrm{x} \leq 0.003$ & $\mathrm{x} \leq 0.03$ \\
\hline 2 & Moderately Safe & $0.01<\mathrm{x} \leq 0.02$ & $0.003<\mathrm{x} \leq 0.005$ & $0.03<\mathrm{x} \leq 0.05$ \\
\hline 3 & Less Safe & $0.02<\mathrm{x} \leq 0.03$ & $0.005<\mathrm{x} \leq 0.01$ & $0.05<\mathrm{x} \leq 0.08$ \\
\hline 4 & Unsafe & $0.03<\mathrm{x} \leq 0.04$ & $0.01<\mathrm{x} \leq 0.015$ & $0.08<\mathrm{x} \leq 0.11$ \\
\hline 5 & Highly Unsafe & $\mathrm{x}>0.04$ & $\mathrm{x}>0.015$ & $\mathrm{x}>0.11$ \\
\hline
\end{tabular}

*the values in the safety model are not multiplied by any of the chosen standard base factor of 1000000, 200000 or 100000 hours-worked/exposures.

**If more than one of the models is used in the prediction, whichever predicts the worst level of safety takes precedence.

the values in the safety model are not in percentage (not yet multiplied by base factor of 100). 


\subsection{Case Study: A Sample of Previous Work Predicted using the Model}

Yusuf et al. [2] investigated accident/injuries cases in industries between 2002 - 2006 and obtained:

(i) total number of injuries as 124 ;

(ii) Unspecified number of death;

(iii) Total man-hour worked as 12440 hours;

(iv) Total man-hour lost as 1244.5 hours (equivalent to 51.85 days).

Using these parameters, we can predict the level of safety of work in the industries investigated as follow:

(i) Using equation (1):

$$
F R R=\frac{124}{12440} \simeq 0.01
$$

From Table 4, we may conclude that the work activity in the industries studied by [2] is very safe.

Using equation (2):

$$
S r=\frac{51.85}{12440} \simeq 0.004
$$

From Table 4, we may conclude that the work activity is moderately safe.

(iii) It is not possible to use Fatality Rate (FAR) for the prediction because the number of death is not known.

\subsubsection{The safety level of work investigated by}

Since the model with the worst level of prediction is recommended, we conclude that the work is moderately safe. Hence, the industries under investigation where such report emanated can be licensed to continue with their production activities. The management only needs to be encouraged to intensify on the standard of their safety rules and general practices to upgrade their industrial operation to a very safe level [2].

\section{CONCLUSIONS}

In this study, SR, FRR and FAR often used as accidents/injuries parameters had been utilized to provide a model for prediction of level of safety of the industrial work activities. The model can be an invaluable tool for researchers and experts on industrial or occupational safety once the relevant data on industrial accidents/injuries can be obtained. The model was used to predict the safety level of the work carried out by [2] as Moderately Safe. The model can provide the need for special monitoring and regulation of the safety performance on job activities in industries to protect the welfare of the workforce.

\section{REFERENCES}

[1] xxx, Global estimates of occupational accidents and fatal work-related diseases in 2014. Workplace Safety \& Health Institute, Singapore, p. 25, Available at: www.wshi.gov.sg/Observatory-WSH-Landscape/ResearchReport.html, (12.12.2016).

[2] Yusuf, T.A., Ismaila, S.O., Kuye, S.I., Samuel, O.D., Evaluation of the cost and effect of industrial accidents, European Journal of Scientific Research, vol. 132 no. 2, 2015, p. 184-190.

[3] Azadeh-Fard, N., Schuh, A., Rashedi, E., Camelio, J.A., Risk assessment of occupational injuries using accident severity grade, Safety Science, vol. 76, 2015, p. 160-167.

[4] Dumrak, J., Mostafa, S., Kamardeen, I., Rameezdeen, R., Factors associated with the severity of construction accidents: The case of South Australia, Australasian Journal of Construction Economics and Building, vol. 13, no. 4, 2013, p. 32-49.

[5] xxx, Glossary of Occupational Health and Safety terms. Industrial Accident Prevention Association, Ontario, Canada, 2007, p. 34, Available at: www.iapa.ca (1.11.2016).

[6] Carrillo-Castrillo, J.A, Rubio-Romeo, J.C., Onieva, L., Causation of severe and fatal accidents in the manufacturing sector, International Journal of Occupational Safety and Ergonomics, vol. 19, no. 3, 2013, p. 423434. 
[7] Schultz, G., Safety management: Using advanced analytics to predict and prevent workplace injuries. Occupational Health \& Safety, 2012, p. 1-2, available at www.ohsonline.com. 